\title{
Sobre o cotidiano no contexto do adoecimento e da hospitalização: o que dizem as mães acompanhantes de crianças com diagnóstico de neoplasia?'
}

\author{
Camila Rebeca Vieira de Almeida, Isabelle Craveiro de Oliveira Leite, Cibele Braga Ferreira, \\ Victor Augusto Cavaleiro Corrêa
}

Universidade Federal do Pará - UFPA, Belém, PA, Brasil.

\begin{abstract}
Resumo: Introdução: O cotidiano é um fenômeno complexo, multidimensional e processual, no qual todas as pessoas estão inseridas, é a medida da sucessão da vida humana, sendo a base constituinte da vida, promovendo o(s) sentido(s) de continuidade da existência. Dentre as doenças infantis, as neoplasias destacam-se por sua alta incidência e repercussões na vida e no cotidiano da criança e de seus familiares ou responsáveis, sendo comum que crianças com neoplasia e seus acompanhantes vivenciem a hospitalização. Objetivo: Considerando a relevância e repercussões do cotidiano vivido para a saúde e bem-estar, objetivamos desvelar os significados da vivência do cotidiano hospitalar para mães de crianças com diagnóstico de neoplasia. Método: Trata-se de uma pesquisa qualitativa, com enfoque fenomenológico, na modalidade análise do conteúdo, a partir da aplicação de entrevistas semidirigidas com nove mães, em um Hospital da Rede Pública. Resultados: Os resultados revelaram que o cotidiano hospitalar pode ser permeado pelo desconforto físico, angústia; medos, incertezas, dificuldades de adaptação às regras, ambiente e procedimentos hospitalares; pela saudade, afastamentos de pessoas, contextos e ocupações significativos; e pelo não fazer ou fazeres vinculados ao cuidado com a criança. Todavia, as pessoas podem buscar (re)significar o cotidiano, através de vivências ocupacionais e relações de apoio entre acompanhantes, o que pode contribuir para a percepção de bem-estar e aprendizagem decorrente desta experiência. Conclusão: Portanto, os sentidos desta vivência e a forma como esta pode interferir na saúde e bem-estar das pessoas devem ser inquietações de terapeutas ocupacionais em hospitais.
\end{abstract}

Palavras-chave: Mães, Hospitalização, Atividades Cotidianas.

\section{The daily life in the context of illness and hospitalization: what say the accompanying mothers of children diagnosed with neoplasia?}

\begin{abstract}
Introduction: Daily life is a complex, multidimensional and processual phenomenon, in which all people are included; it measures the succession of human life, and is the constituent basis of life, promoting the direction (s) of the continuity of existence. Among the childhood diseases, cancer is noted for its high incidence and impact on the lives and daily life of the child and their parents or guardians, being common for children with cancer and their caregivers to experience hospitalization. Objective: Considering the importance and impact of daily living for health hand well-being, we aimed to uncover the meanings of the hospital routine experience for mothers of children diagnosed with cancer. Method: This is a qualitative research with phenomenological content analysis; from the application of semi-structure interviews with nine mothers, in a Public Hospital. Results: The results revealed that the hospital routine can be permeated by physical discomfort, anguish; fears, uncertainties, difficulties in adapting to the rules, environment and hospital procedures; by nostalgia, isolation from people, contexts and meaningful occupations; and tasks linked to the child care. However, people can (re) think the daily life through occupational experiences and supportive relationships between caregivers, which may contribute to the perception of well-being and learning resulting from this experience. Conclusion: Therefore, this experience and the way it can interfere with the health and well-being of people should receive attention from occupational therapists in hospitals.
\end{abstract}

Keywords: Mothers, Hospitalization, Activities of Daily Living.

Autor para correspondência: Victor Augusto Cavaleiro Corrêa, Passagem Pinto Marques, 46, Marambaia, CEP 66615-880, Belém, PA, Brasil, e-mail: victorcavaleiro@gmail.com

Recebido em Jan. 25, 2015; $1^{\text {a }}$ Revisão em Maio 13, 2015; $2^{\text {a }}$ Revisão em Jul. 27, 2015; $3^{\text {a }}$ Revisão em Set. 13, 2015 ; Aceito em Set. 23 , 2015. 


\section{Introdução}

O caso dele é grave. E a cada dia pode piorar. (Esmeralda, sobre o processo de adoecimento do filho).

Este estudo objetivou compreender o cotidiano hospitalar de mães acompanhantes de crianças internadas com diagnóstico de neoplasia, desvelando as percepçôes, sentidos e significados relacionados a esta vivência. De acordo com Kujawsky (1988) apud Takatori (2001, p. 3), a palavra "cotidiano" tem origem no latim, proveniente de quotidianus e, etimologicamente, significa "cada dia", sendo considerada a unidade de medida da sucessão da vida humana, feita de um dia após o outro. Certeau (2009) afirma que cotidiano é o que nos é dado a cada dia, a realidade que partilhamos com as pessoas ao nosso redor e o que nos impulsiona para o "despertar" diário de nossa vida.

Nesse sentido, Novaes (2006) compreende que o cotidiano se desenrola num tempo social, histórico e cultural. Desta forma, entendemos que o cotidiano envolve tanto a repetição de fazeres quanto a vivência do desafio, do surpreendente, que possibilitam a constante aprendizagem e abertura para espaços de criatividade.

Compreendemos o cotidiano como um fenômeno complexo, multifatorial, fluido, sucessivo e continuado, que se apresenta como o elemento que possibilita $\mathrm{o}(\mathrm{s})$ sentido(s) de continuidade da existência, dia após dia. Nesse sentido, Kujawsky (1988) apud Takatori (2001, p. 6) compreende o cotidiano como a base constituinte da vida dos seres humanos, dia após dia, sendo permeado por fazeres, relaçóes, percepçóes, sentimentos e contextos que influenciam o cotidiano e são por ele influenciados. No caso do cotidiano vivido em um hospital, a sucessão dos fazeres diários significativos pode ser bruscamente interrompidas, levando a experiências que causem sofrimentos, incertezas e angústias àqueles que se inserem neste contexto.

O processo de adoecimento e agravamento das condiçôes clínicas geram situaçóes de perdas transitórias e/ou definitivas na vida das pessoas, podendo ocorrer sofrimento, desorganização da vida cotidiana e familiar (OTHERO; PALM, 2010; OTHERO, 2010). A hospitalizaçâo é uma condição extremamente complexa para a criança e para aqueles que a acompanham, pois favorece o afastamento de pessoas e dos contextos significativos, a vivência de perda da autonomia, dentre outras experiências intensas que exigem mobilização para uma adaptação.
Assim, estar hospitalizado, bem como acompanhar a pessoa em situação de hospitalização, pode constituir-se em um momento crítico na vida das pessoas. Segundo Shiotsu e Takahashi (2002, p. 104),

[...] ser acompanhante é estressante, é triste, é cansativo, pois além do desgaste físico, há o desgaste emocional por conviver de perto com o sofrimento [...], a incerteza, a expectativa frente ao tratamento e as dúvidas quanto ao agir e o fazer.

Dentre as doenças infantis, as neoplasias se destacam pela alta incidência e repercussóes na vida e no cotidiano da criança e de seus familiares, geralmente necessitando de hospitalizaçóes em que o tempo de internaçáo varia de acordo com o tipo de neoplasia, a gravidade e/ou o estágio da patologia, o suporte psicossocial e a resposta da pessoa ao tratamento.

É comum que crianças com neoplasia vivenciem, juntamente com seus acompanhantes, situações de hospitalização, seja no momento do diagnóstico, ou durante um período de descompensaçáo do quadro clínico, para a realização de exames, seja ainda pela própria necessidade de tratamento. Desta forma, crianças e mães podem passar a vivenciar intensamente o cotidiano no/do hospital. Observamos que o cotidiano hospitalar pode ser permeado por medos, ansiedades, angústias, rupturas e afastamentos que podem influenciar os fazeres e as percepçóes de crianças e acompanhantes a respeito da imersão em uma cotidianidade diferente da qual era vivida até então.

Ao encontrar-se "um dia após o outro" no hospital, as pessoas passam, mesmo que ainda não se conscientizem deste fato, a se inserir em um cotidiano peculiar. Este fato se torna relevante, pois o cotidiano "promove sentidos de continuidade de existência” (CERTEAU, 2009), ou seja, possibilita a experiência do desenrolar da vida, dia após dia, o que implica nas percepçóes de cada pessoa sobre si mesma, sobre seus fazeres e contextos, e sobre sua existência singular no mundo.

Neste ponto, refletimos: E quando o cotidiano de uma pessoa é atravessado pelo adoecimento de um ente querido, e pela necessidade de hospitalização, quais seráo os possíveis sentidos e percepçóes que passam a ser vivenciados por estar dia após dia no hospital? Será que os sentidos atribuídos a sua existência podem se modificar? Como a existência de cada pessoa (máe acompanhante) passa diante do estar vivenciando o cotidiano no/do hospital? Como a vivência deste cotidiano, que continua sendo base constituinte da vida, interfere na saúde e bem-estar destas pessoas? O que mães que acompanham seus filhos podem nos revelar sobre esta experiência de vida? 
Estas inquietaçóes nos impulsionaram a adentrar nos territórios do cotidiano e relacionar os conhecimentos sobre este fenômeno com a perspectiva de terapeutas ocupacionais, no peculiar contexto hospitalar. O presente trabalho pode ser descrito como um "debruçar-se" sobre o cotidiano vivido no hospital, compreendido como um fenômeno repleto de sutilezas, que necessitam de um olhar aguçado e de uma escuta sensível para serem percebidas, bem como pela compreensão de que é no cotidiano que o engajamento ocupacional se dá e de onde as significaçôes emergem.

O interesse para realização deste estudo surgiu a partir de vivências acadêmicas que proporcionaram visitas a hospitais da rede pública, onde observamos que no ambiente hospitalar, as pessoas necessitavam de uma assistência que não enfatizasse apenas a recuperação física, mas sim que oportunizasse a (re)construção de novas formas de vida, mais intensas, plenas e saudáveis, ao considerar que a pessoa que vivencia a hospitalização, seja ela paciente ou acompanhante, necessita de acesso a oportunidades para alcançar a saúde, o que envolve aspectos físicos, emocionais, sociais, ocupacionais, e assim qualidade do viver; sendo as diversas dimensôes da vida consideradas.

Diante do fato de que ao lidarmos com o cotidiano, as percepçóes e sentidos de quem o vivencia são o foco de análise, esta pesquisa optou em oferecer um lugar de destaque nesta pesquisa às expressôes das mães acompanhantes sobre a vivência do cotidiano hospitalar.

\section{Método}

A gente vê todo o dia uma reação dele. A gente vai ficando mais animada. (Rubi, sobre a gradativa recuperação do filho).

A pesquisa foi desenvolvida em um hospital da Rede Pública, referência no atendimento de pessoas com diagnóstico de neoplasias. As idas ao hospital aconteciam, em média, três vezes por semana. A pesquisa foi desenvolvida no período de três meses, para que a investigação coincidisse com o tempo médio de internação de cada criança no referido hospital. Participaram da pesquisa nove mães acompanhantes de crianças com diagnóstico de neoplasia. Todas as participantes têm vínculo materno com as crianças, situando-se na faixa etária entre 17 e 37 anos, sendo três mães provenientes da Capital do Estado ou da Regiáo Metropolitana, e seis oriundas de localidades no interior do Estado. Para identificar as participantes e seus discursos, utilizamos nomes de pedras preciosas.
Empregamos a abordagem qualitativa, a partir da concepção fenomenológica, em que se buscou compreender a percepção de cada pessoa, que vivencia o cotidiano do/no hospital, a partir da análise de suas falas. Esta perspectiva busca privilegiar a compreensão da vivência de cada participante da pesquisa, considerando o contexto, as formas como cada pessoa adapta-se ou ajusta-se; as maneiras de se inter-relacionar; a sua própria compreensão, seus sentimentos; e como se reconhece na referida situação (VIANA, 2004). Esta abordagem nos permitiu investigar e compreender descriçôes individuais a respeito de um real vivido, logo, algo dinâmico e não quantificável, favorecendo a compreensão das pessoas, do fenômeno (a vivência do cotidiano), num dado contexto (hospitalar).

Elencamos a concepção fenomenológica, pois esta busca a essência de um determinado fenômeno, por meio da descrição deste. A adoção desta concepção proporciona o conhecimento do outro e do mundo, favorecendo o estabelecimento da relaçáo entre pessoa-pessoa, ou seja, a intersubjetividade entre as pesquisadoras e a pessoa que participa da pesquisa (BARGUIL; LEITE, 1997; MORENO; JORGE; GARCIA, 2004).

Neste sentido, Holanda (2003, p. 175) afirma que, ao elencar esta concepção, o pesquisador torna-se um coparticipante, na medida em que suas percepçóes interagem continuamente com seu "objeto" de pesquisa. Nesta perspectiva, buscamos investigar o "fenômeno" tal como se revelou, se apresentou diante de nós, sem que tomássemos como ponto de partida um sistema de verdades com suas premissas ou hipóteses. Assim, neste estudo, buscamos aproximar-nos do revelar de cada participante e, através de suas singularidades, compreender os significados de suas vivências. Deste modo, o foco foi o fenômeno baseado nas experiências vividas no dia a dia de cada acompanhante, considerando que cada pessoa tinha um mundo cotidiano a ser conhecido e a ser descoberto e desvendado.

Inicialmente, foram realizadas visitas com o objetivo de ambientar-se ao cotidiano hospitalar e conhecer as acompanhantes e suas histórias, e convidá-las e selecioná-las para colaboração ao estudo. Em seguida, foram feitas visitas semanais ao hospital, com o intuito de observar a vivência do cotidiano hospitalar das participantes, e para entrevistas semidirigidas com as seguintes perguntas disparadoras: "Como era e como você se sentia no seu dia a dia antes de ser acompanhante deste paciente no hospital?" e "Como é o seu dia a dia atualmente neste hospital e como você se sente a respeito desta vivência?". 
As entrevistas foram gravadas e posteriormente analisadas, compondo as unidades temáticas vinculadas ao conceito de cotidiano: 1) Diante do novo: necessidades de adaptação ao cotidiano hospitalar; 2) Perdas, rupturas, afastamentos e saudades cotidianos e 3) Os fazeres: composiçáo do cotidiano hospitalar.

Adotou-se como metodologia a análise do conteúdo, enfatizando os trechos dos relatos colhidos nas entrevistas sobre as vivências cotidianas como mãe acompanhante de criança com diagnóstico de neoplasia. Buscamos ainda revelar alguns dos gestos, entonações, linguagem corporal e emoções das acompanhantes durante o registro de suas falas. Esta metodologia, segundo Turato (2003, p. 313), "tem o formato mais apropriado para ser utilizado nas pesquisas qualitativas". Assim, em um movimento de aproximação, fomos buscando captar o fenômeno em estudo e os significados atribuídos à vivência do cotidiano no hospital, em meio às vivências expressadas nas falas das participantes. Além disso, procuramos compreender como as falas das entrevistadas iam repercutindo em nós, enquanto pesquisadoras, visto que a pesquisa e, consequentemente, o estar junto destas acompanhantes, também passou a fazer parte de nosso cotidiano.

Concordamos com Viana (2004), quando afirma que os sentidos relativos às vivências de uma pessoa nunca são alcançados em totalidade, sendo assim, a complexidade individual nunca se encerra dentro de uma compreensão. Entendemos que estamos compartilhando compreensôes, que buscam aproximar-se dos sentidos e significados para cada participante sobre o momento vivenciado.

Os procedimentos éticos vigentes foram cumpridos, conforme a Resolução 466/12, do Conselho Nacional de Saúde. O estudo foi submetido aos Comitês de Ética em Pesquisa da Fundação Hospital de Clínicas Gaspar Vianna (FHCGV) e do Hospital Ophir Loyola (HOL). Foi aprovado em março de 2011. Protocolo no 2010/298459.

\section{Resultados e Discussão}

[...] antes a gente andava, brincava, saía. Depois que começou tudo isso, a gente parou [...] (Cristal, sobre o cotidiano anterior à hospitalização).

\subsection{Diante do novo: necessidades de adaptação ao cotidiano hospitalar}

A vivência da hospitalização é, geralmente, experienciada como circunstância de fragilidade e incertezas, inclusive para o acompanhante. Comumente, a pessoa ao saber que necessitará acompanhar um filho em um processo de hospitalização sente preocupaçóes que tendem a girar em torno do diagnóstico, das expectativas de cura, sentimentos de morte iminente e pesares relativos ao afastar-se de casa, cidade, outros filhos, entes queridos, ocupaçóes significativas, dentre outros.

O hospital pode ser percebido como uma realidade formada por procedimentos e regras. Entretanto, "[...] as acompanhantes não vêm para esse local sem uma história de vida [...]” (LIMA; NOBRE, 2008, p. 30). Elas carregam consigo toda uma experiência de vida anterior à hospitalização, tendo que se adaptar à nova situação.

Nesse sentido, o cotidiano é permeado pelas experiências da pessoa, o que inclui tanto o enfrentamento da hospitalização como as relaçóes com outros, as percepçóes sobre o que se vive, bem como a organizaçáo do tempo, no espaço e modos de agir. Compreendemos a cotidianidade como sendo constituída por redes de encontros e trajetórias entrecruzadas (VARELA, 2010). No hospital, diante desse novo ambiente, tâo diferente do lar, observamos que é um desafio a mais para as mães acompanhantes se permitirem habitar aquele espaço, que concretiza a vivência do adoecimento e pode simbolizar para muitas acompanhantes o deixar de viver um dia a dia 'normal'.

Saraceno (1999) e Castro e Mecca (2008) fazem referência à diferença entre 'estar' e 'habitar' um ambiente, afirmando que o 'estar' remete à pessoa em relação a um espaço que nada reflete suas necessidades ou poder de decisão; já o 'habitar' remete a uma apropriação do espaço pela pessoa, o que perpassa por um nível de pertencimento e organização material e simbólica dos espaços e dos objetos, e construção de relaçôes afetivas com as demais pessoas que ali vivem.

Jade expressou algumas dúvidas relacionadas à hospitalização e sua eficácia:

Tem horas que eu choro, imagino, vejo ele alegre, ele sorrindo, brincando. Ai eu imagino, muita gente fala que náo tem cura, não adianta. Tudo isso, deixa a gente assim.

A neoplasia é uma doença culturalmente associada à possibilidade de morte desde o momento do diagnóstico, e percebemos que este sentimento de medo pode ser ampliado diante da necessidade de hospitalização. $\mathrm{Na}$ fala sofrida de Jade, entendemos que este medo é bastante presente em seu dia a dia, no hospital, e é reafirmado pelo imaginário de doença incurável relacionado ao diagnóstico de neoplasia. Podemos perceber também a angústia diante da 
necessidade da internação, e os sentimentos de associação do estar neste lugar com a possibilidade de morte, na fala de Jade:

A familia ficaram tudo agoniado, e eu fiquei aflita. Sofri muito, chorava muito. Pensei que ele [seu filho] ia morrer rápido, era tanta coisa que passava na minha cabeça.

As mudanças que esta vivência impulsionou na vida dessas pessoas também podem ser observadas na fala de Cristal, quando esta nos revela a dificuldade em habitar o ambiente do hospital:

Porque a gente não tá na nossa casa, a gente tá no hospital, ai tudo fica difícil, tudo muda.

Lidar com o diagnóstico de neoplasia de um ente querido e as repercussóes deste podem ser vividos como avassaladores, e a hospitalização pode ser sentida como uma vivência que concretiza este momento de vida, que pode mudar tudo o que havia sido vivido até então.

Tais relatos evidenciam que

[...] o diagnóstico de uma doença com prognóstico reservado traz à tona a fragilidade do ser humano e o contato com sua finitude, lembrando a possibilidade da morte mais próxima [...] (TAKATORI; OSHIRO; OTASHIMA, 2004, p. 261),

afetando diretamente seus acompanhantes.

Muitas acompanhantes nos relataram o quanto estava sendo difícil adaptarem-se ao dia a dia no hospital, sendo os primeiros dias considerados um dos momentos mais delicados, dolorosos e permeados por angústia e sentimentos de tristeza diante do fato inegável de estar vivenciando a situação do adoecimento e hospitalização, conforme observamos no relato de Ametista, que nos disse com a voz embargada:

A gente [ela e a filha] chorava muito. A primeira semana aqui foi horrivel. Eu nunca tinha estado num hospital.

Este fato pode implicar um estranhamento em relação ao ambiente do hospital, com uma não apropriação daquele espaço. As dificuldades para adaptar-se ao novo ambiente também podem ser percebidas na fala de Diamante:

Não, eu náo me imaginava nem entrar aqui nesse hospital. Por que pra mim, eu tenho assim, que ela não tá doente, ainda náo caiu a ficha [...] eu sei lá, fiquei assim desligada, fora do ar, entendeu? Por que nunca imaginei que a minha filha podia ter assim, uma doença tão grave.
Esta percepção e sentimentos repercutiam no modo de agir desta mãe, que permanecia a maior parte do tempo junto à filha. Relatou inclusive que sentia dificuldade em alimentar-se e participar das atividades oferecidas no hospital.

O ambiente do hospital também foi sentido como um lugar estranho para Safira, que nos relatou sobre sua chegada ao local da seguinte forma:

Por náo conbecer ninguém, não sabia como entrar no hospital, mas com os dias, me senti melhor. A acompanhante Cristal também nos revelou que: A gente estranha um pouco o ambiente, a maneira 'das pessoa' tratar a gente; graças a Deus que desde quando a gente chegou aqui que a gente tá tendo o maior apoio.

Para Safira, o fato de não "conhecer ninguém" foi experienciado como um fator que influenciou suas primeiras percepçóes a respeito do ambiente do hospital, citando inclusive que se locomover pelo espaço era algo difícil. E Cristal, neste sentido, confirma a importância de sentir-se acolhida e apoiada pelas pessoas que estavam no hospital, ao chegar àquele lugar onde passaria a viver, dia após dia, durante um período prolongado de tempo.

O cotidiano se constitui como uma processualidade que dá contorno a nossas experiências e, segundo Castro e Mecca (2008), quando permanece em constante transformação, possibilita que a pessoa modifique suas trajetórias de vida; o que pode favorecer um viver enquanto um processo, ao invés de a vida parecer estagnada numa sucessão de mesmos acontecimentos.

Percebemos que o adaptar-se, representado pelo "ir se sentindo melhor", em especial através do acolhimento e construção de vínculos e afetos entre as pessoas que habitavam o hospital, incluindo os profissionais, crianças e demais acompanhantes, auxiliavam na vivência de um cotidiano que não se estagna diante das primeiras impressóes de estranhamento, e favorece um cotidiano aberto para superação, transformação de percepçóes e sentimentos frente à hospitalização, podendo ainda apoiar a acompanhante no enfrentamento desta situação de vida. E se compreendemos o cotidiano no hospital enquanto morada, entendemos que é importante que as pessoas que aí habitam tenham um sentimento de continuidade de existência, tanto em relação aos espaços quanto referentes às relaçóes humanas que possam ser estabelecidas, o que reforça que o cotidiano envolve um aspecto individual, mas também é atravessado pelas condiçôes e relaçôes determinadas social e historicamente, fornecendo a historicidade que determina a situação das pessoas 
na vida cotidiana. Dessa capacidade de estar no mundo, ocorre a configuração de uma cotidianidade.

O hospital como instituição pode ser considerado um espaço concreto no qual as pessoas passam a viver, "comem, dormem, caminham, falam" (SARACENO, 1999; CASTRO; MECCA, 2008). Para Galheigo (2003), ao lidarmos com o cotidiano, também lidamos com a concretude do homem; e observamos que diante do fato de estar/habitar o hospital, as acompanhantes passam a vivenciar um cotidiano que é permeado por questóes concretas de existência, que também podem facilitar ou dificultar o processo adaptativo diante deste novo ambiente.

Sobre a alimentação no hospital, Ametista e Jade nos trouxeram relatos que representam um conteúdo frequente no discurso das acompanhantes. Ametista nos disse:

A alimentaçáo aqui é boa, pra mim, pra ela (filha), tudo bom. Nunca faltou nada [...]. E Jade nos revelou: Olha, no começo, a alimentaçáo eu estranhei um bocado [...] agora não, já tá adaptado um pouquinho.

Outra questão que foi revelada refere-se ao cansaço e desgaste físico, decorrentes do estar vivenciando o cotidiano no/do hospital. Esta foi uma queixa bastante comum nos relatos das máes. O cansaço foi atribuído a fatores como tempo prolongado no hospital; complicaçôes no quadro clínico da criança, e consequente aumento da vigilância e cuidados com ela, inclusive no período noturno. Turquesa nos disse a respeito do desgaste físico sentido após este período no hospital: "[...] agora que o cansaço tá chegando desses 'dia' todinho”. Percebemos que em determinado momento da hospitalização é comum que a acompanhante perceba algum incômodo físico relacionado aos dias vividos no ambiente do hospital; o que pode ser um fator que desfavoreça o bem-estar.

Turquesa nos revelou que, apesar de saber de sua importância ao lado do filho, algumas vezes sente-se cansada durante o processo de adoecimento e internação do ente querido:

Ele tava num jeito que a gente passava a noite todinha sem poder descansar nada. Era dor, febre, vômito, ele não conseguia descansar e nem a gente.

Observamos nesta fala que o quadro clínico da criança influenciava no estado de alerta e falta de descanso de Turquesa. Nesta fala, não ficou evidente, mas muitas mães citavam o fato de que quando havia alguma criança na enfermaria com muita dor, sofrendo, chorando, ou sendo submetida a procedimentos invasivos, em geral as acompanhantes demonstravam não apenas inquietude, mas também se mostravam solidárias e dispostas a enfrentar a situação juntamente com a criança e com sua acompanhante. Num espaço físico pequeno como o das enfermarias, não seria incomum se o fato relatado por Turquesa também tivesse influenciado no descanso das demais acompanhantes que presenciaram sua aflição e de seu filho.

Outro aspecto que pode influenciar na adaptação das mães acompanhantes diante do cotidiano no/do hospital é o vivenciar, mesmo que como espectadora, de procedimentos clínicos e terapêuticos que podem ser algumas vezes invasivos e dolorosos. Muitas ações no ambiente hospitalar consistem em procedimentos que podem ser rotineiros ou de emergência, incluindo-se ainda mortes ocasionais ou iminentes.

As enfermarias, segundo Lima e Nobre (2008), frequentemente são percebidas como um local onde o clima é de tensão, em função das próprias açōes desenvolvidas neste ambiente, em especial vinculadas ao tratamento da criança, em que existem regras que devem ser cumpridas. E os procedimentos, como realização de exames e administração de medicamentos, podem também ser incluídos neste conceito de regras, que são preestabelecidas, devendo ser aceitas muitas vezes de forma passiva, visto que muitas acompanhantes desconhecem informaçóes básicas a respeito dos procedimentos efetivados. Percebemos este fato no relato de Rubi:

Cada coisa que fazem com ele [seu filho] eu me sinto mais aliviada, tá tomando a medicação certa, já passou por cirurgia. Eu já fico mais animada, cada procedimento que fazem com ele me dá mais esperança [...] aí a gente vai ficando mais alegre a cada dia que passa, a gente vai ficando mais animado.

Percebemos que, para esta acompanhante, presenciar os procedimentos sendo efetivados tem um significado especial: representam a busca, a conquista e a aproximaçáo diária da possibilidade de cura de seu filho, o que lhe proporciona ânimo, alegria e esperança que se renovam a cada dia e a cada intervençáo relacionada ao tratamento da criança.

Todavia, também podem ser fonte de sofrimento, conforme os relatos de Jade e Diamante, respectivamente:

É ruim ver toda hora eles furando ele, toda hora eles furam pra tomar soro, pra tomar quimioterapia, 'eita' meu Deus, é muita coisa;

O mais dolorido [...] é ver a criança sofrendo, sentindo dores, por que a medicação dói demais, a 
criança é toda furada, por que às vezes eles não conseguem acertar a veia. É difícil, é muito duro.

Segundo Viana (2004), é frequente que ocorram momentos de terapêuticas invasivas, complicaçóes, efeitos colaterais, procedimentos dolorosos que podem ocasionar na máe acompanhante vivências desagradáveis. Diante de experiências tão sofridas, compreendemos que é delicado pensarmos em plena adaptação, mas é importante perceber que as mães acompanhantes também necessitam de atenção, acolhimento e intervenções multiprofissionais voltadas para essas peculiaridades, em especial nos primeiros dias de vivência do cotidiano no hospital; e nos momentos em que a criança é manipulada, durante procedimentos mais dolorosos e invasivos; visto que para algumas mães acompanhantes este momento pode ser sentido como um momento delicado e difícil.

Diante desta situação, observa-se que, além da alteração do cotidiano destes, acrescenta-se o fato da visualização e do partilhar de situaçôes angustiantes referentes à condição de saúde do seu filho, pois olhar para a criança com equipamentos, sondas e aparelhos agrega ao sofrimento dos pais elementos concretos, intensificando-os (TAKATORI; OSHIRO; OTASHIMA, 2004).

A transição do cotidiano vivido antes da hospitalização para uma vivência cotidiana no hospital é um processo complexo, dinâmico, alinear, pois as mãe chegam ao hospital e ali permanecem imersas em suas histórias, compreensões de vida, sentimentos diante desta situação cujo centro é a doença e a perspectiva de cura da criança; neste contexto, também estão envolvidos os demais membros da família, e assim a complexidade desta situação vai tomando dimensões e repercussôes incomensuráveis, indizíveis, pois não há como definir em uma palavra, com exatidão, o que sentem estas máes acompanhantes. Estas fazem todo um esforço, abdicando do convívio com pessoas e lugares que fazem parte de sua vida, para estar ao lado de um dos membros da família que momentaneamente está mais fragilizado. E, nos dias que vão seguindo, lentos, no hospital, vão tentando adaptar-se e enfrentar o desafio de habitarem o/no hospital.

\subsection{Perdas, rupturas, afastamentos e saudades cotidianos}

A maioria das mães expressou que vivenciou rupturas em sua vida devido ao adoecimento da criança, e posterior vivência do cotidiano hospitalar. $\mathrm{O}$ afastamento do cotidiano em família é algo bastante recorrente nas falas das acompanhantes, que manifestam saudades e desejo de retornar às vivências que costumavam experenciar antes do diagnóstico de neoplasia e da internaçáo.

Para Castro e Mecca (2008), o cotidiano, apesar das mudanças, permanece como pano de fundo que oferece contorno e direção à vida. Assim, entende-se que o cotidiano no hospital, mesmo com tantas rupturas vivenciadas, é o que, ao repetir-se todo dia, sem contudo compactuar com a estagnação da vida e das possibilidades, permite a sensação de continuidade da existência.

É comum ainda que as mães expressem sentimentos de saudade e angústia por estarem longe de suas casas e entes queridos. Ser mãe acompanhante caracteriza-se como uma experiência difícil e dolorosa decorrente da separação do convívio familiar; bem como refere Valle (1997) e Viana (2004), quando dizem que a permanência no hospital pode ser o momento em que a pessoa, ao entrar em contato com a doença, percebe que perdeu seu mundo anterior, sente sua existência ameaçada. Podemos perceber tal aflição nos seguintes relatos:

Ametista expressou:

Sou muito ligada com as minhas filhas, me dedico' muito pra elas, e por esse motivo tá no hospital agora tá sendo muito dificil, porque eu tenho outras duas filbas, e a gente acaba tendo que não dar muita atenção pra elas.

No caso de Ametista, a aflição era dolorosa, pois a família nunca havia experienciado nenhuma situaçáo que os obrigasse a ficar longe uns dos outros. Viana (2004) refere que fatores como a distância, a separação da família e a quebra da rotina do dia a dia revelam-se, frequentemente, em queixas de saudade e justificativas de preocupação com os que ficaram em casa.

Observamos o quanto é importante que as mães acompanhantes possam ter contatos com seus familiares, para que continuem, de certa forma, participando da dinâmica do lar e que possam receber informaçóes a respeito dos entes queridos que estejam distantes, conforme expresso na fala de Safira, sobre o que sente ao ter contato com seus familiares: "mais aliviada porque eles diziam que a minha outra filha estava bem".

Compreendemos que o cotidiano é mais que rotina, repetição e fatos encadeados em continuidade; acreditamos que no cotidiano do hospital é possível, necessário e saudável implementar mudanças e possibilitar novos modos de ser e estar. Acreditamos que no cotidiano do hospital os telefonemas, 
visitas e contatos com os familiares auxiliam a mãe acompanhante a não se sentir tão longe e alheia ao que está ocorrendo em sua casa, com seus projetos e com seus outros filhos. Assim, por exemplo, ao invés de ser mãe ausente, ela poderia ter possibilidades de ser uma mãe que, apesar de distante do lar, continua com domínio, conhecimento e participação nas decisóes, escolhas e preferências sobre o que ocorre em sua casa e com seus familiares.

No relato de Pérola, podemos perceber o quanto é angustiante estar distante de sua casa e de seus entes queridos:

\section{A maneira de tratar a gente aqui eu não tenho o que falar, mas é uma solidáo, uma saudade que é muito forte, porque eu tenho minhas filhas lá, meu marido, toda minha familia mora lá. Ai vem aquela solidão.}

O sentimento se relaciona ao de angústia, que muitas pessoas podem experimentar quando se conscientizam de estarem 'sós', ainda que momentaneamente. O mal-estar pode emergir quando a pessoa descobre a possibilidade da morte em sua vida, tanto a morte propriamente dita, quanto a "morte" das possibilidades da existência, dos desejos, vontades e projetos. Como apoiar, entâo, uma acompanhante que diariamente vivencia sentimentos tâo intensos e potencialmente avassaladores quanto o medo da morte, a saudade e a solidão? Talvez, ao ouvi-las, permite-se a abertura de espaços para que durante o dia a dia as acompanhantes possam expressar a respeito dos seus sentimentos, percepçóes e desejos.

Consideramos, assim, fundamental que as mães tenham no hospital espaços náo apenas para (re)elaborar sentimentos sobre as saudades do lar, mas também que possam construir, criar e efetivar açôes que minimizem os sentimentos de solidão e alheamento sobre o que está ocorrendo com seus entes queridos durante sua ausência do lar.

Boff (2000) nos diz que não importa somente o que nos acontece, mas, sobretudo, as nossas reaçóes frente às circunstâncias. E quando o que ocorre refere-se a situaçôes delicadas e dolorosas, como o adoecimento de alguém querido ou a vivência do cotidiano hospitalar? Diante desta circunstância de vida, as pessoas podem apresentar diversas reaçóes frente aos desafios e experiências cotidianas que vão ocorrendo ao longo do processo de adoecimento e hospitalização do filho, que é permeada por acontecimentos que fogem ao controle das máes que ali estão. Uma das reaçóes que observamos relacionou-se à percepção das acompanhantes sobre o futuro, mesmo o mais imediato (como o dia de amanhã), como algo não apenas incerto, mas também ameaçador e favorecedor de sentimentos de angústia, conforme observamos na fala de Cristal:

\section{A gente fica pensando: o que vai acontecer? Até quando a gente vai aguentar isso?}

Percebemos que o cotidiano das mães acompanhantes pode ser permeado pelas expectativas quanto ao futuro, e que o modo como cada pessoa vai, dia após dia, reagindo diante de um porvir incerto, e às vezes assustador, pode influenciar no cotidiano do/no hospital. Em geral, as crianças que estáo no hospital apresentam frequentes (e às vezes diárias) mudanças abruptas no quadro clínico; e/ou estão sendo submetidas a medidas terapêuticas, que podem gerar sintomas que debilitam temporariamente; e/ou esperando realização de procedimento cirúrgico. Estas vivências cotidianas de inconstância, expectativas referentes à melhora do quadro clínico da criança, esperas, incertezas, podem ser algo extremamente sofrido para essas mães, com repercussóes significativas no desenvolvimento de seus papéis ocupacionais e na construçáo dos projetos de vida, conforme apontam Shiotsu e Takahashi (2002, p. 105),

[...] a doença traz transtornos para toda a família, principalmente para aquele que está como acompanhante, ocasionando mudanças no ritmo de trabalho, nas atividades domésticas, no sono e no repouso.

Diante das incertezas do tratamento e seu processo, condições que podem não acolher as expectativas das acompanhantes de modo satisfatório, o cotidiano pode ser vivido como algo penoso, repleto de angústia, em que, apesar do forte desejo de voltar para junto de seus familiares, contextos e fazeres significativos, pode haver dificuldade em elaborar planos para o futuro, conforme percebemos nas seguintes falas. Pérola nos relatou que:

\section{De agora pra frente, eu náo sei como é que vai ser, depois que ele 'fazer' a cirurgia.}

E Diamante nos revela:

Até então devido a essa doença eu náo tenho projeto nenhum, por que hoje ela pode tá aqui, amanhã sair, depois pode voltar de novo, então não tem como fazer projeto nenhum, só vendo mesmo no dia a dia.

Diamante também nos revela não conseguir realizar projetos para o futuro, e atribui este fato ao adoecimento da filha e ao receio de que, mesmo que a filha apresente uma melhora clínica, possa ter a necessidade de retornar ao hospital em algum outro momento de vida. E neste esperar, neste não saber, 
o cotidiano no hospital parece ir se arrastando... Pode ir ganhando contornos de um momento de vida difícil, que pode repercutir inclusive no pós-alta, visto que o medo das possíveis recidivas, recaídas, agravamento da doença e /ou reinternaçôes pode se fazer presente em seu cotidiano, mesmo após a saída do hospital e retorno para o lar.

Algumas acompanhantes, segundo Viana (2004, p. 27), ao adentrarem no universo de adoecimento e hospitalização do filho, "desesperam-se, ficando sem condiçóes de enfrentar este contexto". Também percebemos nesta pesquisa que lidar com um cotidiano extremamente inconstante, em que em alguns momentos a mãe acompanhante observa melhoras no quadro da criança, e alegra-se, aumentando suas forças e esperança, mas que em outros dias a criança pode apresentar-se debilitada, sem vontade de alimentar-se, com dor, pode repercutir no estado da acompanhante, favorecendo vivências cotidianas que podem ser sentidas e percebidas como desesperadoras, conforme notamos na fala de Esmeralda:

É só desespero, no momento é só desespero. A cada dia, o quadro dele [do filho] vai abaixando [...] no momento eu náo penso no futuro, a minha vida tá entorno dele, a nossa vida; mexeu com toda a familia.

Esta mãe sofria muito com a perda de controle sobre sua vida e incertezas relacionadas à cura do filho, que apresentava uma recaída de leucemia. Esmeralda relatou que após a primeira internaçáo, imaginava que seu filho já estava curado, e em um intervalo de quatro anos, período entre internaçóes, viveu uma vida "normal". $\mathrm{Na}$ atual internação, acreditava que seu filho poderia não suportar o retorno da doença. Em meio a este contexto, como não se sentir desesperada?

A vida cotidiana é compreendida, segundo Castro, Lima e Brunello (2001, p. 48), como "pano de fundo, a linha de referência pela qual podemos nos orientar". Para estas mães, por estarem vivenciando momentos delicados e dolorosos, e lidarem cotidianamente com incertezas e inconstâncias, o cotidiano imediato pode ser vivido permeado por medos, angústias, aflições, desespero, alternados com alguns momentos de alegrias, esperanças, expectativas relacionadas à cura do filho; o que pode favorecer dificuldades em pensar e planejar o futuro, em como será o dia de amanhã. Muitas perspectivas e projetos futuros parecem suspensos, já que o foco passa a ser a criança adoecida e a busca (ou espera) incessante pela superação deste momento de vida.

Acreditamos que deva ser bastante angustiante viver um dia a dia permeado por estes sentimentos, portanto, é fundamental que os profissionais que atuam em hospitais possam favorecer às mães que acompanham seus filhos uma escuta, acolhida e suporte que auxiliem no conhecimento acerca da neoplasia, de forma individualizada, sobre as possibilidades reais de recidiva, de como é possível ter uma vida saudável após a hospitalização, e de que a adaptação saudável ao cotidiano do/no hospital também perpassa pela capacidade de essas mães continuarem planejando seus futuros.

\subsection{Os fazeres: composição do cotidiano hospitalar}

Ao analisarmos a cotidianidade das mães, percebemos que era importante observarmos as percepçóes pessoais, as condiçóes de vida, o lugar que ocupam no hospital, as relações aí estabelecidas; e também as ocupaçôes nas quais (não) se envolvem cotidianamente, bem como o que significa (não) se envolver nesses fazeres.

Para Castro e Mecca (2008), as atividades apresentam um caráter de ancoragem e sustentação. As atividades que são realizadas ao longo da vida vão permeando a cotidianidade das pessoas, oferecendo contornos que possibilitam a sensação de continuidade da existência, já que muitas vezes o que fazemos se confunde com o que somos. Daí considerarmos a importância da realizaçáo de atividades significativas para as mães acompanhantes, para que a passagem pelo hospital seja mais saudável e enriquecedora.

Ao nos referirmos aos fazeres cotidianos, sinalizamos que elas perpassam pela concretude e (inter)subjetividades/afetividades presentes no ambiente do hospital. Na cotidianidade, enquanto permeada de ocupaçôes que possibilitam contornos à existência e potência de vida, as pessoas iam (não) se identificando com as possibilidades ocupacionais que o ambiente do hospital oferecia e/ou permitia, ao mesmo tempo em que eram influenciadas por suas histórias e repertório ocupacionais e pela interação com o outro.

Compreendemos que a vivência do cotidiano no hospital favorece o afastamento de ocupaçôes antes realizadas, mas também observamos que pode, por vezes, (des)motivar o envolvimento em ocupaçóes de interesse e/ou significativas, já que o envolvimento em ocupações tem estreita relação com as condiçôes de vida e, neste caso específico, observamos que se relaciona com a vivência do papel de cuidadora, que está no hospital para acompanhar, cuidar da criança com as flutuaçôes clínicas; e com as limitaçôes e 
afastamentos favorecidos por estarem dia após dia no hospital.

Ao cuidar do outro, a pessoa ocupa-se, co-ocupa-se, preocupa-se, envolve-se afetivamente. E diante de uma situaçáo dolorosa, o cuidado pode tornar as relaçôes e os espaços mais acolhedores e habitáveis. O cuidar é, ainda que veladamente para a consciência, "seletivo", pois individual e/ou coletivamente, as pessoas "escolhem" o que ou quem vai estar sob seus cuidados, aproximando-os e afastando-o de sua cotidianidade, de seu mundo vivido, de sua atenção e interesse.

Para Othero (2010), o adoecimento de um familiar funciona com uma situaçáo de impacto. Quando a criança adoece, a máe pode ficar como se estivesse adoecida, visto que ela também vivencia momentos traumáticos e angustiantes, pois como apontam Shiotsu e Takahashi (2002), o acompanhante, assim como o enfermo, também manifesta sentimentos e emoções como expectativas, ansiedades, medos, preocupaçóes e receios. Como acompanhante, ela pode sentir-se responsável, mas também vulnerável, visto o seu reconhecimento como cuidadora, conforme podemos perceber no relato de Esmeralda:

No começo a gente [ela e o marido] tava revesando, mas agora ele [o filho] náo aceita outra pessoa a não ser eu mesma. Eu já entendo ele, a gente já conviveu vinte e quatro horas, a gente não desgruda um do outro.

Neste sentido, Diamante nos disse:

Meu dia a dia é vinte e quatro horas pra ela [a filha], por que não é que eu não possa sair, eu posso sair, mas só que náo tenho confiança de deixar outra pessoa com ela, entendeu?

Nestas falas, percebemos que em decorrência da hospitalização, afastados de pessoas e ocupaçóes significativas, ambos no enfrentamento de uma patologia em geral grave, imersos em um tratamento por vezes invasivo, doloroso física e emocionalmente, os vínculos entre máe e filho podem ser de tal forma fortalecidos, que a presença e cuidados da acompanhante pode ser significada por ela e/ou pela criança como extremamente necessária, encorajadora, sustentadora, essencial para lidar com os desafios cotidianos que se apresentam, inclusive o medo da morte de seu filho. A máe se percebe e/ou é percebida pela criança como a melhor pessoa que poderia estar desempenhando o papel de acompanhante.

E se esta atividade de cuidar já era evidente na vida anterior dessas mães acompanhantes, torna-se ainda mais intensa no cotidiano hospitalar, como percebemos na fala de Safira:

\section{Muita saudade de cuidar dele, que é a coisa que eu mais gosto de fazer, cuidar dele, mesmo aqui no hospital.}

Observamos ainda que mesmo quando as mães possuíam tempo para disponibilizar para si mesmas, como para os autocuidados, surgiam conversas nos corredores com profissionais e com outras acompanhantes, busca de informaçôes sobre a doença dos filhos, atividades oferecidas no hospital que pudessem compor o cotidiano no hospital, ainda assim muitas preferiam a observação, o estar ao lado de seus filhos, como vemos no relato de Pérola:

As crianças precisam de atençâo, às vezes assim quando eles [as crianças] dormem, a gente não tem nada pra fazer, ai se tivesse alguma coisa era bom, pra gente fazer, aprender, né? Mas, ele [o filho] tem que ter muita atenção, por que eles são bebezinhos, [...] às vezes a gente não tem tempo pra fazer as atividades por causa disso, por causa da atenção deles.

Para Pérola, as possibilidades de se envolver em outros fazeres que não fossem o cuidar do filho, eram possíveis, desejáveis, desde que se adaptassem aos momentos em que a criança estivesse dormindo. Ao contrário do que normalmente concebemos quando pensamos no cotidiano hospitalar de uma acompanhante, Pérola percebia que algumas vezes não tinha tempo para realizar outras atividades. Assim, neste relato foi evidenciado que o cuidar era a ocupação prioritária, e que no dia a dia outras formas ocupacionais eram preteridas diante da necessidade e satisfação de cuidar da criança a quem acompanha.

Compreendemos que as mães acompanhantes reconheciam a importância de estarem ao lado dos filhos, experienciando este momento difícil em suas vidas, o que culminava em um cotidiano permeado por fazeres vinculados aos cuidados voltados às crianças.

Neste sentido, era comum observarmos alguma criança que estava restrita ao leito, e quando olhávamos para o seu lado, víamos uma mãe que, apesar de poder ausentar-se de perto da criança por alguns instantes, preferia ficar ali, parada, como que numa suspensão de horas, quando o importante era não o fazer com a criança, e assim compartilhar, estar junto, parecendo, a princípio, não estar fazendo nada. Quando na realidade estava tomando para si parte das limitaçóes e da sofrer da criança.

No hospital, observamos que para algumas mães era algo difícil se afastar, mesmo que momentaneamente, dos fazeres relacionados ao cuidar da criança, e as vivências ocupacionais não relacionadas a este cuidar eram experienciadas gravitando no entorno deste 
fazer principal (já descrito anteriormente), ou seja, ocorria o envolvimento em outros fazeres quando, no cotidiano, eram percebidos alguns momentos em que a acompanhante podia "afastar-se" de sua ocupação de cuidadora, para viver outras formas ocupacionais. Podemos perceber este fato nos seguintes relatos:

\section{Cristal nos disse:}

Só ver televisão, é a única distração [...] é só, aqui no hospital, e de vezes em quando sair pra lavar, pra cuidar das coisinhas dela; mas é um pouquinho complicado [...] Eu pego a biblia pra ler de vez em quando, a gente fica passeando pelo corredor [risos], só isso, e ver televisão. Rubi nos revelou: Quando ele [o filho] 'ta' bem, de manhã a gente levanta, toma banho, ai ele faz curativo, ai eu lavo minha roupa que eu visto, não tem quem lave; ai a gente [ela e o filho] almoça e vai só dormir [...]. E Diamante relatou: [...] tem só alguns livros, revistas que a gente pega ali na copinha só isso, tirando isso, a televisão que distrai um pouco.

Além deste fato, algumas mães acompanhantes relataram que não sentem vontade de se envolver em ocupaçōes, como Diamante:

Náo sinto vontade pra nada aqui. O tempo que en tiver aqui vou ficar o tempo todo perto dela [...] mas o meu dia a dia aqui é bem, só com aquele tédio de ficar presa aqui, sem saber de nada lá fora.

No hospital, observamos que as vivências ocupacionais podem marcar a passagem do tempo, dáo contornos à experiência existencial das mães acompanhantes, e podem atuar como redes de sustentação e suporte, que passam a compor uma parte das histórias de vida, situaçóes que vão sendo construídas pela passagem pelo hospital. Todavia, também observamos que, para algumas mães, as ocupaçóes experienciadas no hospital podem ser percebidas como fazeres que acabam por reafirmar a imersão no mundo da doença, um lugar de espera, de passividade, de conformismo, de sobrevivência, e não de produção de potência de vida do cotidiano no hospital.

Estas compreensões tornam-se especialmente importantes para o terapeuta ocupacional, que, para Quarentei (2007, p. 10-11), tem o papel de

[...] caprichar a vida, buscando possibilitar a vivência de atividades que aumentem a potência de vida, que favoreçam a 'apreciação dos fazeres', e dos gestos, cheiros, sabores, valores envolvidos nestas açôes.
Neste sentido, é um profissional que pode favorecer o "re-criar da vida", numa perspectiva de olhar e buscar intervir no campo da simplicidade, acolhendo o "continuum de re-fazer-se e traduzir-se em atividades". Compreendemos que buscar compreender o cotidiano das mães acompanhantes no hospital, ao mesmo tempo simples e complexo, como o palco onde as suas vivências ocupacionais se desenrolam, pode facilitar que o terapeuta seja um articulador entre os desejos, interesses das mães acompanhantes, e as possibilidades e limitaçóes vinculadas ao contexto hospitalar, permitindo assim que este momento de vida seja repleto de construçôes de espaços, lugares e vivências de saúde, descobertas, aprendizagens, (re)significaçôes... nas/através/a partir das ocupaçóes cotidianas. Segundo Castro, Lima e Brunello (2001, p. 48), a vida se mostra como:

Leque de açóes rotineiras, o que faz com que associemos o conceito de bem-estar a um vasto campo de atividades humanas no qual as necessidades relacionam-se a uma rede multifacetada de extrema complexidade e dependente de uma série de vivências sociais e culturais.

Neste sentido, as vivências cotidianas no hospital podem não proporcionar experimentaçóes em fazeres significativos, o que pode repercutir na percepção de satisfação, bem-estar e saúde das mães acompanhantes. Este fato acaba por culminar em falas repletas de lamentação e tristeza, como a de Jade, que demonstrando uma feição sofrida nos disse: "e a vida é quase que dentro do hospital".

Assim, a vida cotidiana que se desenrola no hospital deve ser cuidada, observada e compreendida, pois as repercussóes desta vivência podem influenciar não apenas no bem-estar pontual, ou seja, durante a hospitalização, mas também pode ter ressonâncias na volta para o lar e expectativas quanto a possíveis reinternações.

\section{Conclusão}

Analisar o cotidiano hospitalar vivenciado pelas mães acompanhantes e as percepçóes e significados que permeiam essa experiência compuseram o eixo norteador de nossa pesquisa. Compreendemos que é necessário favorecer a conscientização e reflexão sobre as estratégias (que podem ser) usadas por mães acompanhantes para lidar com seus conflitos cotidianos. Entendemos, assim, que propiciar às mães acompanhantes a (re)significação de seu cotidiano hospitalar, de seus fazeres, sentimentos e 
percepçóes é um desafio cotidiano para os terapeutas ocupacionais que atuam neste campo.

Entendemos que ao vivenciar o contexto hospitalar, tanto as crianças internadas quanto suas mães acompanhantes não somente experimentam rupturas no cotidiano que vivenciavam antes da situação de hospitalização, mas também passam a viver intensamente o cotidiano no/do hospital. Observamos a importância de que ao acompanhante seja oferecido um espaço para possibilitar a expressão de seus sentimentos e percepções acerca da vivência do cotidiano hospitalar, favorecendo a reelaboração de tal experiência, refletindo sobre os seus significados e como esta vivência se insere em sua história de vida. Deste modo, possibilitam-se espaços que favorecem tanto (re)significação do cotidiano vivenciado no hospital e também uma transcendência deste.

Consideramos essencial ampliar as práticas hospitalares, em especial no que se refere às intervençōes terapêuticas ocupacionais, para que os atendimentos e atividades terapêuticas não sejam voltados apenas para os pacientes, mas que, cada vez mais, amplie este olhar para os seus acompanhantes, reforçando a necessidade de se conhecer, compreender e ajudar estas pessoas a refletirem sobre a vivência no cotidiano hospitalar, sobre as ocupaçóes que se desenrolam nesta cotidianidade, e como esta situação se insere na história de vida dessas pessoas.

Neste sentido, compreendemos que o terapeuta ocupacional é um profissional que se volta para a promoção da saúde e da qualidade do viver ocupacional. Logo, pode valer-se de seu olhar e conhecimentos para auxiliar na possível (e muitas vezes necessária) (re)significação das percepçôes relativas à situação de vivência do cotidiano hospitalar, de modo que os acompanhantes também possam expressar seus sentimentos e enfrentar melhor o dia a dia no hospital.

Acreditamos que as intervençôes com foco nos fazeres, percepçóes e sentidos envolvidos no cotidiano estão de acordo com formas humanizadas de atuar no contexto hospitalar, considerando os acompanhantes como pessoas ativas, atores e autores de suas impressões, ações (e quem sabe criações?) cotidianas.

Notamos ainda, que a hospitalização, caso não seja assim compreendida, pode ser uma experiência potencialmente crítica, que se não (re)significada, pode repercutir inclusive nas vivências após a alta hospitalar, em especial quando se trata da hospitalizaçáo infantil, e em relação a situaçóes de adoecimento que favorecem constantes reinternaçôes.

Neste sentido, o terapeuta ocupacional, ao intervir com o foco no cotidiano, necessita considerar seu potencial transformador como ato de saúde que favorece o criar e o preencher, cotidiano, da vida das pessoas. E é importante que este profissional, junto com equipe de saúde, favoreça cotidianamente espaços para a vivência de fazeres criativos, afetivos, e para a construção/expressão de significados, percepções e reflexóes a respeito do que se vive e do que (não) se faz no hospital.

E, como facilitador deste processo de enriquecimento das vivências cotidianas das mães acompanhantes, o terapeuta ocupacional pode, em seu próprio cotidiano profissional, ir, como nas palavras de Oliveira (2007, p. 1), aprendendo "nos/dos/com os cotidianos a ver/ler/ouvir/sentir o mundo".

\section{Referências}

BARGUIL, P. M.; LEITE, R. C. M. Voltemos às próprias coisas: o convite da fenomenologia. In: BARRETO, J. A. E.; MOREIRA, R. V. O. Imaginando erros. Fortaleza: Casa José de Alencar, 1997. p. 79-111.

BOFF, L. Saber cuidar: ética do humano. Compaixão pela terra. Petrópolis: Vozes, 2000.

CASTRO, E. D.; MECCA, R. C. Experiência estética e cotidiano institucional: novos mapas para subjetivar espaços destinados à saúde mental. Interface - Comunicação, Saúde, Educação, Botucatu, v. 12, n. 25, p. 377-386, 2008.

CASTRO, E.; LIMA, E.; BRUNELLO, M. I. Atividades humanas e Terapia Ocupacional. In: CARLO, M.; BARTALOTTI, C. (Org.). Terapia Ocupacional no Brasil: fundamentos e perspectivas. São Paulo: Plexus Editora, 2001. p. 41-62.

CERTEAU, M. A invenção do cotidiano: artes de fazer. Petrópolis: Editora Vozes, 2009.

GALHEIGO, S. M. O cotidiano na terapia ocupacional: cultura, subjetividade e contexto históricosocial. Revista de Terapia Ocupacional da USP, São Paulo, v. 14, n. 3, p. 104-109, 2003.

HOLANDA, A. Fundamentação fenomenológica da pesquisa do vivido. In: CONFERÊNCIA INTERNACIONAL SOBRE FILOSOFIA, PSIQUIATRIA E PSICOLOGIA, 2003, Brasília. Anais... Brasília: ABRAFIPP, 2003. p. 173-181.

LIMA, R. M. S.; NOBRE, S. C. N. Grupo terapêutico com mäes acompanhantes de crianças com câncer: um enfoque da terapia ocupacional. 2008. $93 \mathrm{f}$. Trabalho de Conclusão de Curso (Graduação em Terapia Ocupacional) - Universidade do Estado do Pará, Belém, 2008.

MORENO, R. L. R.; JORGE, M. S. B.; GARCIA, M. L. P. Fenomenologia - fenômeno situado: opção metodológica para investigar o humano na área da saúde. Revista de Enfermagem Escola Anna Nery, Rio de Janeiro, v. 8, n. 3, p. 348-353, 2004. 
NOVAES, M. O. Conhecendo mulheres: um estudo exploratório sobre gênero, cotidiano e dor crônica. 2006. 92 f. Dissertação (Mestrado em Ciências Biológicas) Universidade do Vale da Paraíba, São Paulo, 2006.

OLIVEIRA, I. B. Aprendendo nos/dos/com os cotidianos a ver/ler/ouvir/sentir o mundo. Revista Educação \& Sociedade, Campinas, v. 28, n. 98, p. 47-72, 2007.

OTHERO, M. B. Assistência ao familiar da pessoa com Câncer. In: OTHERO, M. B. Terapia Ocupacional: práticas em Oncologia. São Paulo: Roca, 2010. p. 111-122.

OTHERO, M. B.; PALM, R. D. C. M. Terapia Ocupacional em Oncologia. In: OTHERO, M. B. Terapia Ocupacional: práticas em Oncologia. São Paulo: Roca, 2010. p. $72-110$.

QUARENTEI, M. S. Do ocupar à criação de territórios existenciais. In: CONGRESSO BRASILEIRO DE TERAPIA OCUPACIONAL, 10., 2007, Goiânia. Anais... Goiânia: Associação dos Terapeutas Ocupacionais de Goiás, 2007. CD-ROM.

SARACENO, B. Libertando identidades: da reabilitação psicossocial à cidadania possível. Belo Horizonte: Instituto Franco Basaglia/TeCorá, 1999.

SHIOTSU, C. H.; TAKAHASHI, R. T. O acompanhante na instituição hospitalar: significado e percep- ções. Revista da Escola de Enfermagem da USP, São Paulo, v. 34, n. 1, p. 99-107, 2002.

TAKATORI, M. A Terapia Ocupacional no processo de reabilitação: construção do cotidiano. O Mundo da Saúde, São Paulo, v. 25, n. 4, p. 371-377, 2001.

TAKATORI, M.; OSHIRO, M.; OTASHIMA, C. O hospital e a assistência em Terapia Ocupacional com a população infantil. In: DE CARLO, M. M. R. P.; LUZO, M. C. M. (Org.). Terapia Ocupacional: reabilitação física e contextos hospitalares. São Paulo: ROCA, 2004. p. 256-275.

TURATO, E. R. Tratado da metodologia da pesquisa clínico - qualitativa: construção teórico epistemológica, discussão comparada e aplicação nas áreas da saúde e humanas. Petrópolis: Vozes, 2003.

VALLE, E. R. M. Câncer infantil: compreender e agir. Campinas: Editorial Psy, 1997.

VARELA, R. C. B. Crianças com deficiência: compreendendo seu cotidiano e a importância do uso de recursos tecnológicos na atençáo em Terapia Ocupacional. 2010. 226 f. Dissertação (Mestrado em Ciências da Reabilitação) - Universidade de São Paulo, São Paulo, 2010.

VIANA, L. G. Mães - acompanhantes de filhos no tratamento de câncer: um estudo compreensivo. 2004. $162 \mathrm{f}$. Dissertação (Mestrado em Psicologia Clínica) - Universidade Católica de Pernambuco, Recife, 2004.

\section{Contribuição dos Autores}

Camila Rebeca Vieira de Almeida e Isabelle Craveiro de Oliveira Leite participaram do projeto, da coleta, análise e discussão dos dados, além da elaboração do texto. Victor Augusto Cavaleiro Corrêa coordenou e orientou o trabalho. Todos os autores participaram da revisão do texto e aprovaram sua versão final.

\section{Notas}

${ }^{1} \mathrm{O}$ material apresentado é parte de pesquisa realizada para composição de Trabalho de Conclusão de Curso de Graduação em Terapia Ocupacional. Os procedimentos éticos vigentes foram cumpridos, conforme a Resolução 466/12, do Conselho Nacional de Saúde. Foi submetido aos Comitês de Ética em Pesquisa em Seres Humanos da Fundação Hospital de Clínicas Gaspar Vianna (FHCGV) e do Hospital Ophir Loyola (HOL). Protocolo no 2010/298459. 